\title{
Peak exercise response in relation to tissue depletion in patients with chronic obstructive pulmonary disease
}

\author{
E.M. Baarends*, A.M.W.J. Schols*, R. Mostert**, E.F.M. Wouters*
}

Peak exercise response in relation to tissue depletion in patients with chronic obstructive pulmonary disease. E.M. Baarends, A.M.W.J. Schols, R. Mostert, E.F.M. Wouters. OERS Journals Ltd 1997.

ABSTRACT: In several studies a correlation between body weight and peak exercise capacity has been found in patients with chronic obstructive pulmonary disease (COPD). In the present study a thorough analysis of the relationship between body composition and peak exercise performance was executed in 62 patients with clinically stable COPD. This was based on the hypothesis that particularly muscle mass, as the largest constituent of both fat-free mass (FFM) and body cell mass, is related to exercise capacity.

Body composition was assessed using deuterium and bromide dilution techniques, to measure total body water (TBW) and extracellular water. From these measurements FFM:TBW/0.73, the ratio of ECW/intracellular water (ICW) and ICW-index (ICW/height ${ }^{2}$ ) were calculated. Peak exercise performance was measured using an incremental cycle ergometry test.

The transfer factor of the lung for carbon monoxide $(T \mathrm{~L}, \mathrm{CO})$ intrathoracic gas volume (ITGV), maximal expiratory and inspiratory mouth pressure, forced expiratory volume in one second (FEV1), FFM-index (FFM/height'2), body mass index (weight/ height $\left.^{2}\right)$ and $I C W$-index correlated strongly $(p<0.01)$ to peak oxygen consumption $\left(V^{\prime} \mathrm{O}_{2}\right)$. The ratio ECW/ICW correlated only weakly, but significantly, with peak $V^{\prime} \mathrm{O}_{2}$ $(\mathrm{r}=-\mathbf{0 . 2 5}, \mathrm{p}<\mathbf{0 . 0 5})$. Stepwise regression analysis demonstrated that FFM-index and $T \mathrm{~L}, \mathrm{CO}$ explained $53 \%$ of the variation in peak $V^{\prime} \mathrm{O}_{2}$. The results of this study furthermore indicate that severe FFM depletion is related to a blunted tidal volume response to peak exercise, a decreased peak oxygen pulse and an early anaerobic metabolism in patients with COPD.

Depletion of muscle mass, measurable by assessment of fat-free mass, significantly effects peak oxygen consumption, ventilatory response, the oxygen pulse and anaerobic energy metabolism in patients with chronic obstructive pulmonary disease. Eur Respir J 1997; 10: 2807-2813.
*Dept of Pulmonology, Maastricht University, Maastricht. **Asthma Center Hornerheide, Horn, The Netherlands.

Correspondence: E. Baarends

Dept of Pulmonology

University Hospital Maastricht

P.O. Box 5800

6202 AZ Maastricht

Keywords: Body composition chronic obstructive pulmonary disease exercise

Received: February 251997

Accepted after revision September 31997

This study was supported by a grant of the Dutch Asthma Foundation (project number: 91.38)
Among the overall pattern of functional impairment in patients with chronic obstructive pulmonary disease (COPD), limitation of peak exercise capacity is an essential feature, which can be accurately determined by incremental cycle ergometry [1]. The impaired exercise capacity in COPD patients has long been ascribed to an impaired ventilatory capacity due to disturbed pulmonary mechanics, respiratory muscle dysfunctioning, impaired gas exchange and cardiovascular dysfunctioning. Recent publications have drawn attention to peripheral muscle weakness and an altered muscle energy metabolism as contributing factors to impaired exercise capacity $[2,3]$. Muscle strength and metabolism are closely related to body composition [4]. It could be hypothesized that the association between peripheral muscle weakness and alterations in muscle metabolism with exercise impairment is partly related to depletion of muscle mass.

Muscle mass is the largest constituent of the body cell mass (BCM), the energy-exchanging part of the body. The $\mathrm{BCM}$ and the extracellular fluids and solids of the body represent the fat-free mass (FFM). Direct measurement of muscle mass, for instance by magnetic resonance imaging, requires expensive, sophisticated instrumentation, that is not readily accessible [5]. Dilution methods are the next most accurate methods in the hierarchy of body composition methods [5] that can be applied to estimate muscle mass, by the assessment of FFM. The additional value of measurement of FFM instead of body weight in the functional characterization of patients with COPD was demonstrated in an earlier study which showed that FFM correlated stronger with the 12 min walking distance than body weight [6]. In addition, in this previous study it was found that normal weight patients with a selective loss of FFM expressed a lower walking distance than underweight patients with a relative preservation of FFM [6].

In a recent study it was shown, however, that measurement of FFM may mask the loss of BCM in some COPD patients [7]. From this study it was hypothesized that subtle changes in the BCM can be estimated by the extracellular water (ECW)/intracellular water (ICW) ratio, and it was found that an increased ECW/ICW ratio may occur particularly in patients with severe FFM depletion [7]. 
Earlier studies have shown a significant relationship between body weight and maximal exercise capacity in patients with COPD [8-10]. The primary aim of the present study was to investigate the relationship between tissue depletion and peak exercise capacity in COPD, thus, to study whether measurements of FFM or BCM, the latter estimated by ICW, are better predictors of peak exercise capacity than body weight. In addition, the relationship between the ECW/ICW ratio and peak exercise capacity was analysed in order to study the additional effect of a specific, subtle, depletion of ICW (BCM), in case this could not be identified from the difference in correlation between ICW or FFM with peak exercise capacity. The secondary aim of the present study was to analyse the influence of tissue depletion on the ventilatory, cardiac and lactate response to peak exercise in patients with COPD.

\section{Materials and methods}

\section{Patients}

Sixty two patients (44 male, 18 female) with moderate to severe COPD (defined by the American Thoracic Society [11]) were studied (table 1). They were admitted to a pulmonary rehabilitation centre in a stable clinical condition. Patients exhibiting an increase in forced expiratory volume in one second (FEV1) greater than $10 \%$ of baseline after inhalation of $\beta_{2}$-agonists were excluded. None of the patients suffered from a respiratory tract infection or demonstrated clinically visible signs of oedema at the time

Table 1. - Characteristics of the study groups, according to gender

\begin{tabular}{lccc}
\hline & $\begin{array}{c}\text { Total group } \\
(\mathrm{n}=62)\end{array}$ & $\begin{array}{c}\text { Males } \\
(\mathrm{n}=44)\end{array}$ & $\begin{array}{c}\text { Females } \\
(\mathrm{n}=18)\end{array}$ \\
\hline Age yrs & $63 \pm 9$ & $65 \pm 7$ & $58 \pm 10^{*}$ \\
FEV1\% pred & $39 \pm 13$ & $37 \pm 13$ & $45 \pm 13 *$ \\
FVC \% pred & $87 \pm 16$ & $84 \pm 16$ & $93 \pm 14$ \\
IVC \% pred & $85 \pm 16$ & $82 \pm 16$ & $93 \pm 13^{* *}$ \\
TL,CO \% pred & $59 \pm 21$ & $57 \pm 22$ & $64 \pm 17$ \\
KCO \% pred & $69 \pm 26$ & $68 \pm 28$ & $72 \pm 20$ \\
TLC \% pred & $122 \pm 17$ & $121 \pm 18$ & $124 \pm 13$ \\
ITGV \% pred & $165 \pm 36$ & $165 \pm 39$ & $163 \pm 27$ \\
RV \% pred & $189 \pm 51$ & $189 \pm 52$ & $190 \pm 51$ \\
$P$ a,O $\mathrm{O}_{2} \mathrm{kPa}$ & $9.9 \pm 1.1$ & $9.9 \pm 1.0$ & $9.8 \pm 1.3$ \\
$P \mathrm{I}, \mathrm{max} \mathrm{cmH} \mathrm{H}_{2} \mathrm{O}$ & $74 \pm 21$ & $78 \pm 20$ & $65 \pm 20^{*}$ \\
$P \mathrm{E}, \mathrm{max} \mathrm{cmH} \mathrm{H}_{2} \mathrm{O}$ & $84 \pm 22$ & $87 \pm 21$ & $78.2 \pm 23$ \\
$\mathrm{BMI} \mathrm{kg} \cdot \mathrm{m}^{-2}$ & $23.2 \pm 4.1$ & $23.3 \pm 3.9$ & $22.9 \pm 4.5$ \\
FFM index kg $\cdot \mathrm{m}^{-2}$ & $16.1 \pm 1.9$ & $16.6 \pm 1.7$ & $14.9 \pm 1.8^{* * *}$ \\
FM \% weight & $29.2 \pm 9.3$ & $27.5 \pm 8.9$ & $33.5 \pm 9.3 *$ \\
ECW/TBW \% & $44 \pm 5$ & $44 \pm 5$ & $45 \pm 4$ \\
\hline
\end{tabular}

Values are presented as mean $\pm S D$. FEV1: forced expiratory volume in one second; FVC: forced vital capacity; IVC: inspiratory viral capacity; $T \mathrm{~L}, \mathrm{CO}$ : transfer factor of the lung for carbon monoxide; KCO: TL,CO divided by the alveolar space; TLC: total lung capacity; ITGV: intrathoracic gas volume; RV: residual volume; $\mathrm{Pa}_{\mathrm{a}} \mathrm{O}_{2}$ : arterial oxygen pressure; $P \mathrm{I}$,max: maximal inspiratory mouth pressure; $P$ E,max: maximal expiratory mouth pressure; BMI: body mass index; FFM: fat-free mass index; FM: fat mass; ECW: extracellular water; TBW: total body water. *: $\mathrm{p}<0.05 ; * *: \mathrm{p}<0.01, * * *: \mathrm{p}<0.001$ for differences between males and females. of the study. The patients did not require supplemental oxygen (resting arterial oxygen tension $\left(\mathrm{Pa}, \mathrm{O}_{2}\right)>7.3 \mathrm{kPa}$ ), and had no known cardiovascular, neurological, endocrine or locomotor diseases. The patients were fully informed of the nature and purpose of the study and gave informed consent. The study was approved by the Ethics Committee of Maastricht University. Procedures followed, were in accordance with the Helsinki declaration of 1977, revised in 1983.

\section{Pulmonary function tests}

Flow volume measurements included FEV1, forced vital capacity (FVC) and inspiratory vital capacity (IVC). The highest value of at least three measurements was used. Total lung capacity (TLC), intrathoracic gas volume (ITGV) and airways resistance (Raw) were measured by a bodyplethysmograph (Masterlab, Jaeger, Wurzburg, Germany). The values were expressed as a percentage of a reference value [12]. The transfer factor of the lungs for carbon monoxide $((T \mathrm{~L}, \mathrm{CO})$ and adjusted for alveolar volume: the carbon monoxide transfer coefficient $(K \mathrm{CO})$ ) was measured by a single breath method, and expressed as a percentage of the reference value [12]. Inspiratory and expiratory muscle strength was assessed by maximal inspiratory and expiratory mouth pressures (PI,max and PE,max respectively) according to the method described by BLACK and HyatT [13]. $P \mathrm{I}$, max measurements result in a negative pressure, but in the present study they were expressed and analysed as positive values. Blood was drawn from the brachial artery at rest while breathing room air. $P \mathrm{a}, \mathrm{O}_{2}$ was analysed on a blood gas analyser (Radiometer, ABL 330 Copenhagen, Denmark).

\section{Body composition}

Body height was determined to the nearest $0.5 \mathrm{~cm}$ (Lameris, WM 715, Breukelen, The Netherlands) with subjects standing barefoot. Body weight was measured with a beam scale to the nearest $0.1 \mathrm{~kg}$ (SECA, Germany) with subjects barefoot and in light clothing. To adjust body weight for body height, the body mass index (BMI) was calculated as weight/height ${ }^{2}$.

To measure total body water (TBW) each patient received a weighted $1 \mathrm{~g} \cdot \mathrm{L}^{-1}$ estimated TBW [14] oral dose of deuterium labelled water $\left(\mathrm{D}_{2} \mathrm{O}\right.$ : 99.84 atom percentage excess) mixed into approximately $50 \mathrm{~mL}$ water. For the estimation of ECW, $60 \mathrm{mg}$ bromide $(\mathrm{Br}) \cdot \mathrm{L}$ estimated $\mathrm{TBW}^{-1}$, as sodium bromide $(\mathrm{NaBr})$ was added to the deuterium dose. Patients received this "cocktail" late in the evening around 22:00 h. Just before and approximately 10 $\mathrm{h}$ later, a venous blood sample and a urine sample were obtained $[15,16]$. Patients were not allowed to eat or drink during equilibration.

Urine was analysed for deuterium with an isotope ratio mass spectrometer, according to the standard Maastricht protocol [15]. Deuterium dilution space was calculated from the quantity of administered $\mathrm{D}_{2} \mathrm{O}$ and the urine $\mathrm{D}_{2} \mathrm{O}$ concentrations following complete distribution. TBW was calculated from these values by applying a conversion factor of 1.04. This correction accounts for the exchange of labile hydrogen which occurs in humans during the equilibrium period [17]. FFM was calculated assuming a 
hydration factor of 0.73 . Analogous to the BMI, FFM was adjusted for body height by calculating the FFM index (FFM/height ${ }^{2}$ ).

Bromide concentration in serum ultrafiltrate was determined using high performance liquid chromatography (HPLC) (Spectroflow 783: ABI analytical kratos division, Rotterdam, The Netherlands), according to the anionexchange chromatographic method $[16,18]$. ECW was estimated by the corrected bromide space (CBS) and calculated according the following formula $[16,18]$ :

$$
\mathrm{ECW}(\mathrm{CBS}) \mathrm{L}=\frac{\text { Brdose mmol }}{(\mathrm{Brf}-\mathrm{Brb}) \mathrm{mmol} \cdot \mathrm{L}^{-1}} \times 0.90 \times 0.95
$$

where Brdose is the exact dosage the patients received, Brf is the final bromide concentration in the serum ultrafiltrate (after $10 \mathrm{~h}$ of equilibrium), Brb is the background bromide concentration from the initial blood sample. The correction factor for the $\mathrm{Br}$ in the nonextracellular sites is 0.90 , and the correction factor for the Donnan equilibrium is 0.95 .

ICW was the difference between TBW and ECW, and the ICW index was calculated to adjust for body height (ICW/height ${ }^{2}$ ).

\section{Exercise testing}

The incremental cycle ergometry test (CET) was performed on an electromagnetic braked ergometer (Corival 400, Lode, Groningen, The Netherlands). After a 2 min baseline resting period and a 1 min unloaded cycling, power was increased every minute by $10 \mathrm{~W}$. The load cycled was unknown to the patients, and they were encouraged to cycle for as long as possible.

During the initial resting period and throughout the CET metabolic and ventilatory parameters (Oxyconbeta; Jaeger b.v., Bunnik, The Netherlands) were measured breath by breath, using a breathing mask. Cardiac frequency $(f \mathrm{C})$ was measured with a sport-tester (PE3000; Polar Electro cy, Kempele, Finland), and an infra-red electrode was placed on the finger to measure oxygen saturation (Fasttrac, Sensor Medics Co, Anaheim, CA, USA). The equipment was calibrated prior to the test.

Two minutes after the peak load was reached, a venous blood sample was obtained and stored at $\pm 4^{\circ} \mathrm{C}$. The blood was centrifuged within $2 \mathrm{~h}$ and lactate concentration in plasma was determined using an enzymatic method [19] by an automated system (Cobas Mira; Roche, Bazel, Switzerland).

In the analysis, peak oxygen consumption $\left(V^{\prime} \mathrm{O}_{2}\right)$ rather than peak load was used as a measure of exercise capacity, because peak $V^{\prime} \mathrm{O}_{2}$ is related to the actual ability to diffuse oxygen and to the amount of metabolic active tissue mass. Moreover, peak $V^{\prime} \mathrm{O}_{2}$ is more reproducible than peak load [1].

\section{Data analysis}

The characteristics of the patients are given as mean \pm SD. Differences between groups were calculated with an unpaired student t-test. Stepwise regression analysis was performed to define variables which determined exercise capacity. Analysis of covariance was used when appropriate. Values were considered statistically significant at 0.05 .

In order to test whether patients with a different body composition had a significantly different peak exercise response, the patients were divided into groups of patients with a specific degree of FFM depletion. The cut-off point was determined on the basis of our earlier definition of FFM depletion using FFM adjusted for ideal body weight [20] (female: FFM ð63\% of ideal body weight, male: FFM $ð 67 \%$ of ideal body weight). To avoid the use of wrist circumference (as a rather abitrary measure of frame size) and reference tables, we adjusted FFM for body height (FFM index), as suggested by VanItallie et al. [21]. Subsequently, the FFM index which corresponded to the earlier defined value for FFM/ideal body weight, by means of linear regression analysis, was used in the present study. FFM depletion was thus defined as follows: female: FFM index ð15 $\mathrm{kg} \cdot \mathrm{m}^{-2}$, male: FFM index ð16 $\mathrm{kg} \cdot \mathrm{m}^{-2}$.

\section{Results}

As shown in table 1, the patients in this study suffered from moderate to severe airflow obstruction (FEV1: 39 \pm $13 \%$ pred), most patients were characterized by chronic hyperinflation at rest (ITGV: $165 \pm 36 \%$ pred) and had an impaired transfer factor (TL,CO: $59 \pm 21 \%$ pred). Females were significantly younger than males, which could explain why the lung function (IVC and FEV1) in the female group was superior, although respiratory muscle strength $(P \mathrm{I}, \mathrm{max}$ and $P$ E,max $)$ was inferior.

Peak-load cycled was $56 \pm 23 \mathrm{~W}$, and peak $V^{\prime} \mathrm{O}_{2}$ was $906 \pm 256 \mathrm{~mL} \cdot \mathrm{min}^{-1}$ which corresponds to $43 \pm 20 \%$ pred (peak load) and $56 \pm 16 \%$ pred (peak $V^{\prime} \mathrm{O}_{2}$ ) [22]. Mean peak $V^{\prime}$ E was $37 \pm 10 \mathrm{~L} \cdot \mathrm{min}^{-1}$, or $96 \pm 23 \%$ pred [23], indicating that during the exercise test most patients reached their predicted peak minute ventilation $\left(V^{\prime} \mathrm{E}\right)(=37.5 \times \mathrm{FEV} 1)$ [23].

The body composition of this group varied widely; BMI ranged $15.3-34.4 \mathrm{~kg} \cdot \mathrm{m}^{-2}$. As expected, females had a significantly higher fat mass (FM) than males, and a significantly lower FFM index. TBW relative to body weight was close to normal both in males $(53 \pm 6 \%$ weight $)$ and females (49 $\pm 7 \%$ weight) [24]. Compared to data in a healthy young population, obtained by the same methods as in the present study [25], ECW/weight was also normal $(23 \pm 3 \%$ weight $)$ in the patients of the present study, which together with a normal TBW as percentage of weight implies a normal absolute ECW, but the ECW/TBW ratio was above the highest ECW/TBW ratio in healthy persons [25] in a substantial number of the patients (males 21 patients $>44 \%$, females: three patients $>48 \%$ ).

\section{Correlation between lung function, body composition and} peak $\mathrm{V}^{\prime} \mathrm{O}_{2}$

In table 2 the correlation coefficients between peak $V^{\prime} \mathrm{O}_{2}$ and lung function under resting conditions, and measurements of body composition are shown. Peak $V^{\prime} \mathrm{O}_{2}$ correlated best with TL,CO (\% pred: $\mathrm{r}=0.55, \mathrm{p}<0.001)$ and to a 
Table 2. - Correlation between peak oxygen consumption $\left(V^{\prime} \mathrm{O}_{2}\right)$ and lung function or body composition

\begin{tabular}{|c|c|}
\hline & $\begin{array}{l}\text { Peak } V^{\prime} \mathrm{O}_{2} \\
\mathrm{~mL} \cdot \mathrm{min}^{-1}\end{array}$ \\
\hline \multicolumn{2}{|l|}{ Lung function } \\
\hline FEV $1 \%$ pred & $0.35 * *$ \\
\hline FVC $\%$ pred & 0.10 \\
\hline IVC \% pred & 0.07 \\
\hline$T \mathrm{~L}, \mathrm{CO} \%$ pred & $0.55 * * *$ \\
\hline ITGV \% pred & $-0.47 * * *$ \\
\hline $\mathrm{Pa}_{\mathrm{a}} \mathrm{O}, \mathrm{kPa}$ & $0.28^{*}$ \\
\hline$P_{\mathrm{I}, \max } \mathrm{cmH}_{2} \mathrm{O}$ & $0.43 * *$ \\
\hline$P$ E, max $\mathrm{cmH}_{2} \mathrm{O}$ & $0.46 * * *$ \\
\hline \multicolumn{2}{|l|}{ Body composition } \\
\hline $\mathrm{BMI} \mathrm{kg} \cdot \mathrm{m}^{-2}$ & $0.56 * * *$ \\
\hline FFM index $\mathrm{kg} \cdot \mathrm{m}^{-2}$ & $0.57 * * *$ \\
\hline ICW index $\mathrm{L} \cdot \mathrm{m}^{-2}$ & $0.54 * * *$ \\
\hline ECW/ICW & $-0.25 *$ \\
\hline
\end{tabular}

ICW: intracellular water. $*: \mathrm{p}<0.05 ; * *: \mathrm{p}<0.01, * *: \mathrm{p}<0.001$. For further definitions see table 1 .

lesser degree with KCO (\% pred: $\mathrm{r}=0.49$, p<0.001). Subsequently ITGV ( $\mathrm{r}=-0.47, \mathrm{p}<0.001)$, residual volume (RV) $(\mathrm{r}=-0.45, \mathrm{p}<0.01)$ and $P$ E, $\max \left(\mathrm{cmH}_{2} \mathrm{O}: \mathrm{r}=0.46, \mathrm{p}<0.001\right)$ all correlated best with peak $V^{\prime} \mathrm{O}_{2}$. Finally, $P \mathrm{I}$,max $\left(\mathrm{cmH}_{2} \mathrm{O}\right.$ : $\mathrm{r}=0.43, \mathrm{p}<0.01)$ and FEV1 $(\mathrm{r}=0.35, \mathrm{p}<0.01)$ correlated significantly with peak $V^{\prime} \mathrm{O}_{2}$. There was no significant correlation between $R$ aw and exercise capacity.

With respect to the body composition, peak $V^{\prime} \mathrm{O}_{2}$ correlated significantly with the BMI $\left(\mathrm{kg} \cdot \mathrm{m}^{-2}: \mathrm{r}=0.56, \mathrm{p}<0.001\right)$ and FFM index $\left(\mathrm{kg} \cdot \mathrm{m}^{-2}: \mathrm{r}=0.57, \mathrm{p}<0.001\right)$. ICW index could not improve the correlation with peak $V^{\prime} \mathrm{O}_{2}\left(\mathrm{~kg} \cdot \mathrm{m}^{-2}\right.$ : $\mathrm{r}=0.54, \mathrm{p}<0.001)$ compared to the FFM index. The ratio ECW/ICW correlated weakly but significantly with peak $V^{\prime} \mathrm{O}_{2}(\mathrm{r}=-0.25, \mathrm{p}<0.05)$.

\section{Prediction variables for peak $\mathrm{V}^{\prime} \mathrm{O}_{2}$}

All parameters in table 2 which correlated with a $\mathrm{p}<0.01$ were entered in a step-wise regression model, with peak $V^{\prime} \mathrm{O}_{2}$ as the dependent variable. From the variables entered in the regression model, FFM index $(\mathrm{p}<0.001)$ was selected first, and accounted for $31 \%$ of the variation of peak $V^{\prime} \mathrm{O}_{2}$. After FFM index, TL,CO $(\mathrm{p}<0.001)$ was included in the model, whereas the FEV1, ITGV, PI,max, $P$ E, max, BMI and ICW index were excluded. Together FFM index and TL,CO explained $53 \%$ of the variation of peak $V^{\prime} \mathrm{O}_{2}$.

The relationships between these variables and peak $V^{\prime} \mathrm{O}_{2}$ are demonstrated in figure 1 .

To gain more insight into the influence of a disturbed body composition on peak exercise performance, the difference in response to peak exercise between depleted and nondepleted patients was examined.

\section{Exercise response in patients with or without FFM deple- tion}

There were 26 (10 females, 16 males) patients with a depletion of FFM and 36 (eight females, 28 males) patients with no depletion of FFM.
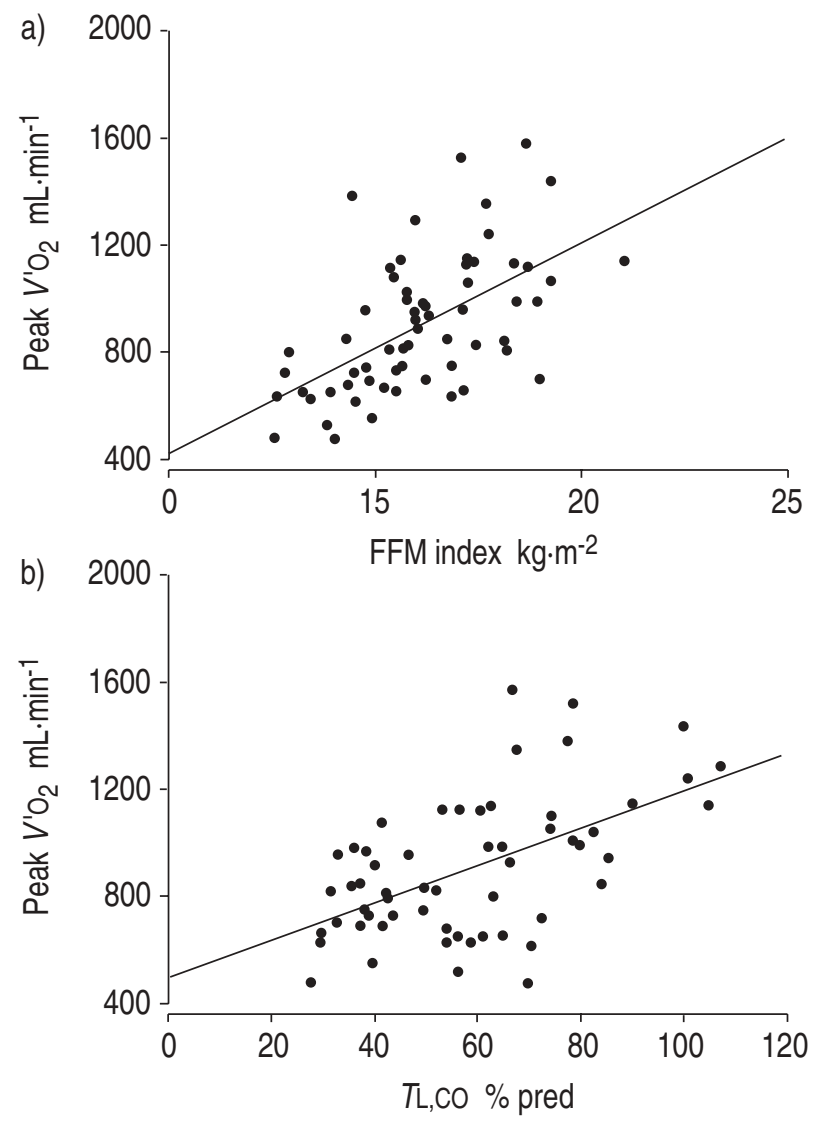

Fig. 1. - Peak oxygen consumption $\left(V^{\prime} \mathrm{O}_{2}\right)$ related to the fat-free mass (FFM) index and the transfer factor of the lung for carbon monoxide $(T \mathrm{~L}, \mathrm{CO})$. The correlation coefficient of the relationship between $V^{\prime} \mathrm{O}_{2}$ and a) the FFM index; and b) the $T$ L,CO was 0.57 and 0.55 , respectively, $(\mathrm{p}<0.001)$.

Patients with or without FFM wasting had no significantly different FEV1 (depleted: $36 \pm 11 \%$ pred, nondepleted: $41 \pm 15 \%$ pred) or TL,CO (depleted: $53 \pm 16 \%$ pred, nondepleted: $63 \pm 22 \%$ pred), but significantly different TLC (depleted: $128 \pm 14 \%$ pred, nondepleted: $117 \pm 17 \%$ pred, $\mathrm{p}<0.05)$.

As shown in table 3 , next to the expected significant differences in body composition and peak $V^{\prime} \mathrm{O}_{2}$ between patients with or without depletion of FFM, there was also a significant difference between the two groups in peak $V^{\prime} \mathrm{E}$, peak $V \mathrm{~T}$, increase in $V \mathrm{~T}$, peak oxygen pulse and the peak lactate/peak load ratio. Peak $V^{\prime} \mathrm{E}$ and the increase in $V \mathrm{~T}$ were still significantly different between the patients with or without FFM depletion $(\mathrm{p}<0.05)$ when a relationship with FEV1 (\% pred) and the increase in $V \mathrm{~T}(\mathrm{p}<0.05)$ and $V^{\prime} \mathrm{E}(\mathrm{p}<0.001)$ was considered.

The peak oxygen pulse (peak $V^{\prime} \mathrm{O}_{2} /$ peak $f$ C) was significantly different $(\mathrm{p}<0.01)$ between the patients with or without FFM depletion when the contribution of TL,CO (\% pred, $\mathrm{p}<0.01)$ to the variation of the oxygen pulse was taken into account.

The peak lactate/peak load ratio tended to be nonsignificantly different $(\mathrm{p}=0.06)$ between the groups of patients differentiated by FFM depletion, when the contribution of TL,CO (\% pred, $\mathrm{p}<0.05)$ was taken into account. 
Table 3. - Exercise capacity compared between groups of patients with different body compositions

\begin{tabular}{|c|c|c|}
\hline & $\begin{array}{l}\text { Depleted } \\
(\mathrm{n}=26)\end{array}$ & $\begin{array}{l}\text { Nondepleted } \\
\quad(\mathrm{n}=36)\end{array}$ \\
\hline$\overline{\mathrm{BMI}} \mathrm{kg} \cdot \mathrm{m}^{-2}$ & $20.5 \pm 2.6$ & $25.1 \pm 3.8 * * *$ \\
\hline FFM index $\mathrm{kg} \cdot \mathrm{m}^{-2}$ & $14.5 \pm 1.0$ & $17.3 \pm 1.3 * * *$ \\
\hline Peak load $\%$ pred & $40 \pm 21$ & $46 \pm 18$ \\
\hline Peak $V^{\prime} \mathrm{O}_{2} \mathrm{~mL} \cdot \mathrm{min}^{-1}$ & $755 \pm 205$ & $1015 \pm 235 * * *$ \\
\hline Peak $V^{\prime} \mathrm{O}_{2} \%$ pred & $55 \pm 13$ & $58 \pm 19$ \\
\hline $\begin{array}{l}\text { Peak } V^{\prime} \mathrm{O}_{2} / \mathrm{FFM} \\
\mathrm{mL} \cdot \mathrm{min}^{-1} \cdot \mathrm{kg}^{-1}\end{array}$ & $18.8 \pm 4.4$ & $20.4 \pm 4.5$ \\
\hline Peak $V^{\prime}$ E L $\cdot \mathrm{min}^{-1}$ & $32.4 \pm 8.6$ & $39.6 \pm 9.8^{* *}$ \\
\hline Peak $V$ 'E/MVV \% & $94 \pm 20$ & $97 \pm 26$ \\
\hline Peak $V$ T L & $1050 \pm 241$ & $1227 \pm 257 * *$ \\
\hline Peak $V$ T-Rest $V$ T L & $324 \pm 197$ & $512 \pm 225^{* *}$ \\
\hline Peak $f$ R breaths min $^{-1}$ & $31 \pm 7$ & $33 \pm 6$ \\
\hline Peak $f$ C beats $\cdot \mathrm{min}^{-1}$ & $127 \pm 16$ & $130 \pm 17$ \\
\hline $\begin{array}{l}\text { Peak oxygen pulse } \\
\text { mL beat }^{-1}\end{array}$ & $6.0 \pm 1.6$ & $7.7 \pm 1.7 * * *$ \\
\hline $\begin{array}{l}\text { Peak lactate/ } \\
\text { peak work load } \\
\mathrm{mmol} \cdot \mathrm{L}^{-1} \cdot \mathrm{W}^{-1}\end{array}$ & $0.09 \pm 0.06$ & $0.06 \pm 0.03 *$ \\
\hline Desaturation \% & $-3.5 \pm 3.3$ & $-3.4 \pm 3.1$ \\
\hline
\end{tabular}

Values are presented as mean $\pm \mathrm{SD} . V^{\prime} \mathrm{O}_{2}$ : oxygen consumption; FFM: fat-free mass; $V^{\prime} \mathrm{E}$ : minute ventilation; MMV: predicted maximal voluntary ventilation; $V \mathrm{~T}$ : tidal volume; $f \mathrm{R}$ : respiratory frequency; $f \mathrm{C}$ : cardiac frequency; $*, * *, * * *: \mathrm{p}<0.05, \mathrm{p}<0.01$, $\mathrm{p}<0.001$ versus depleted group. For further definitions see legend to table 1.

\section{Discussion}

This study shows that depletion of FFM significantly contributes to a disturbed peak exercise capacity in COPD patients, in addition to diffusing capacity. FFM index correlated better with peak exercise capacity than BMI and ICW index, as demonstrated on stepwise regression analysis. A weak but significant correlation was found between ECW/ICW ratio and peak exercise capacity. In addition, it was demonstrated that depletion of FFM contributes to a blunted $V$ T response to peak exercise. Furthermore, a decreased peak oxygen pulse and an earlier anaerobic metabolism during peak exercise appear to be related to FFM depletion in COPD.

A decrease in body weight and FFM in COPD is primarily a consequence of a disturbed energy balance. In a recent study, we demonstrated an increased total daily energy expenditure in COPD patients compared to healthy subjects [26]. Furthermore, in an earlier study we found a lower energy intake, in absolute terms as well as expressed as a percentage of resting energy expenditure (REE), in weight-losing patients compared to weight-stable patients [27]. Caloric deprivation generally leads to a selective atrophy of type II or fast twitch (glycolytic) fibres in muscles [4]. This contributes to the decreased respiratory [28] and peripheral [29] muscle strength in depleted COPD patients, which in turn may affect exercise capacity [2]. In addition, patients with COPD may suffer from a selective depletion of FFM, despite a normal body weight [20]. The reason for a selective FFM depletion is not yet clear, but it probably explains why the FFM index correlated better with peak $V^{\prime} \mathrm{O}_{2}$ than the BMI, as demonstrated on stepwise regression analysis.
As in our earlier study [7], the present study confirms that fluid shifts (increased ECW/ICW ratio), can occur in clinically stable COPD patients. Because the TBW and ECW as a percentage of the body weight of the patients with COPD was similar to healthy persons, and the patients showed no signs of peripheral oedema, it is unlikely that the patients suffered from an absolute expansion of ECW. This means that a relative increase of ECW can be interpreted as a selective depletion of ICW, or BCM. Evidence for a selective decrease in BCM and no absolute ECW expansion in patients with COPD was found earlier in a study by TelFer et al. [30]. In that study a slightly enhanced exchangeable sodium and a pronounced decreased exchangeable potassium was reported, with a normal TBW in patients with COPD. It is unclear which mechanisms might contribute to a relative increase in ECW in patients with COPD. With respect to a possible explanation of a selective decrease in ICW (or cellular shrinkage), the theories posited by HäUSSINGER et al. [31] are interesting. Following this theory, factors such as an inflammatory state, amino acid starvation and stress conditions lead to cellular shrinkage which in turn can act as a catabolic signal. Particularly in depleted patients with COPD, a chronic inflammatory state has been demonstrated [32], which might support the proposed mechanisms by HäussINGER et al. [31], but underlying causes for a relatively increased ECW in patients with COPD need further investigation.

Compared to a healthy young population, $39 \%$ of the patients had a relatively increased ECW. Nevertheless, the ICW index did not predict the peak $V^{\prime} \mathrm{O}_{2}$ better than FFM index. In addition, the ECW/ICW ratio correlated only weakly with peak $V^{\prime} \mathrm{O}_{2}$. Therefore, the results of this study suggest that subtle depletion of BCM masked by FFM measurement is not severe in patients with COPD, since it does not affect exercise capacity to a great extent. However, we cannot exclude the possibility that the present study underestimates the effect of muscle mass depletion on exercise performance due to the methodology used, i.e. measurement of BCM by ICW, because it should be remarked that ECW also represents a part of muscle [5].

The relationship between $T \mathrm{~L}, \mathrm{CO}$ and peak $V^{\prime} \mathrm{O}_{2}$ is evident, since it represents lung parenchymal damage. Besides, it confirms the significant relation between $T \mathrm{~L}, \mathrm{CO}$ and peak exercise performance found in many other studies [2, 33-35].

The results of this study are similar to those of our earlier study in which it was shown that FFM was an important determinant of the 12 min walking distance in COPD patients [8]. However, in our previous study we did not measure the influence of FFM depletion on the metabolic, cardiac and ventilatory response to exercise. In addition, a drawback of our previous study was that a walking test was used. Walking tests are considered less reliable as a measurement of exercise capacity since they are highly subject to effects of learning and motivation [36], whereas in the present study an incremental cycle test was used which is usually acknowledged as the "gold standard" for the measurement of aerobic capacity.

The results of the present study also correspond with earlier studies which showed that a reduced weight is related to a decreased maximal exercise performance [2, 8-10], but these studies did not involve measurements of body composition. Only in the study of CoTes et al. [33], it 
was reported that FFM improved the prediction of peak $V$ $\mathrm{O}_{2}$ in COPD patients, together with variables concerning pulmonary function (airflow and diffusion) and age. However, the latter study was mainly focused on the accuracy of predicting exercise capacity by different pulmonary function variables, and the potential importance of depletion of FFM with respect to exercise capacity was not discussed.

Analysis of the response to peak exercise between depleted and nondepleted COPD patients demonstrated a different ventilatory response to peak exercise between the groups differentiated by FFM depletion. Although the patients in both groups achieved a comparable peak $V^{\prime} \mathrm{E} \%$ pred, the patients with depletion of FFM specifically had an impaired ability to increase $V \mathrm{~T}$, even when the contribution of FEV 1 to $V \mathrm{~T}$ was taken into account. The $f \mathrm{R}$ was not significantly different between the groups differentiated by FFM index. These findings are in agreement with a recent study of Palange et al. [10], who showed that patients with a lower body weight demonstrate a less efficient breathing pattern (a higher deadspace/ $V \mathrm{~T}$ ratio). In general, the blunted $V \mathrm{~T}$ response to peak exercise in COPD patients could be explained by dynamic hyperinflation, but this may be further complicated by the respiratory muscle weakness observed in depleted patients with COPD [28].

Despite comparable exercise-induced desaturation, the patients with severe depletion of FFM demonstrated a significantly lower oxygen pulse than the patients with no depletion of FFM. In addition, oxygen pulse was still significantly different between patients differentiated by FFM depletion when the influence of TL,CO to the variation in oxygen pulse was taken into account. It could be hypothesized that depletion of FFM affects the stroke volume, i.e. decreases the pump ability of the heart. This hypothesis is supported by the study of LANDS et al. [37], who found a decreased stroke volume relative to an increased $f \mathrm{C}$ during exercise in anorectic patients. Further studies of cardiac output measurement during exercise are needed to confirm this interpretation of a decreased oxygen pulse in depleted COPD patients.

Finally, it should be noted that peak lactate concentration per achieved peak work load was significantly higher in the patients with a depletion of FFM than patients with no depletion of FFM, which tended to persist when the influence of TL,CO was taken into account. Evidence for an earlier anaerobic energy metabolism in the patients with excessive tissue wasting in the present study is in agreement with the study of KUTSUZWA et al. [38], who found an early activation of anaerobic glycolysis in patients with COPD, and demonstrated a significant correlation between indices of this early activation and body weight and muscle mass in COPD patients. Furthermore, PALANGE et al. [10] found an earlier onset of metabolic acidosis in patients with a low body weight.

In conclusion, fat-free mass depletion is an important determinant of exercise capacity in patients with chronic obstructive pulmonary disease. The results of the present study warrant further investigation on the possible role of fat-free mass depletion in the recently found interrelationships between peripheral muscle strength, anaerobic muscle metabolism and a blunted tidal volume response and (peak) exercise capacity in chronic obstructive pulmonary disease.

\begin{abstract}
Acknowledgement: The authors would like to thank M.A. Akkermans for technical assistance during the exercise testing.
\end{abstract}

\section{References}

1. Noseda A, Carpiaux JP, Prigogine T, Schmerber J. Lung function, maximum and submaximum exercise testing in COPD patients: reproducibility over a long interval. Lung 1989; 167: 247-257.

2. Gosselink R, Troosters T, Decramer M. Peripheral muscle weakness contributes to exercise limitation in COPD. Am J Respir Crit Care Med 1996; 153: 976-980.

3. Maltais F, Simard A, Simard C, Jobin J, Descagnés P, LeBlanc P. Oxidative capacity of the skeletal muscle and lactic acid kinetics during exercise in normal subjects and in patients with COPD. Am J Respir Crit Care Med 1996; 153: 288-293.

4. McRussel DM, Walker PM, Leiter LA, et al. Metabolic and structural changes in skeletal muscle during hypocaloric dieting. Am J Clin Nutr 1984; 39: 503-513.

5. Baumgartner RN. Body composition in elderly persons: a critical review of needs and methods. Progr Food Nutr Sci 1993; 17: 223-260.

6. Schols AMWJ, Mostert R, Soeters PB, Wouters EFM. Body composition and exercise performance in patients with chronic obstructive pulmonary disease. Thorax 1991; 46: 695-699.

7. Baarends EM, Schols AMWJ, Marken-Lichtenbelt WD, Wouters EFM. Analysis of body water compartments in relation to tissue depletion in clinically stable patients with chronic obstructive pulmonary disease. Am J Clin Nutr 1997; 65: 88-94.

8. Wilson DO, Rogers RM, Wright EC, Anthonisen NR. Body weight in chronic obstructive pulmonary disease. Am Rev Respir Dis 1989; 139: 1435-1438.

9. Gray-Donald K, Gibbons L, Shapiro SH, Martin JG. Effect of nutritional status on exercise performance in patients with chronic obstructive pulmonary disease. Am Rev Respir Dis 1989; 140: 1544-1548.

10. Palange P, Forte S, Felli A, Galassetti P, Serra P, Carlone S. Nutritional state and exercise tolerance in patients with COPD. Chest 1995; 107: 1206-1212.

11. American Thoracic Society. Standards for the diagnoses and care of patients with chronic obstructive pulmonary disease (COPD) and asthma. Am Rev Respir Dis 1987; 137: 225-228.

12. Quanjer Ph, Tammeling GJ, Cotes JE, Pedersen OF, Peslin R, Yernault J-C. Standardized lung function testing. Eur Respir J 1993; 6 (Suppl. 16): 5-40.

13. Black LF, Hyatt RE. Maximal respiratory pressures: normal values and relationship to age and sex. Am Rev Respir Dis 1969; 99: 696-702.

14. Deurenberg P, Westrate JA, Seidell JC. Body mass index as a measure of body fatness: age and sex specific prediction formulas. Br J Nutr 1991; 65: 105-114.

15. Westerterp KR, Wouters L, Marken Lichtenbelt WD. The Maastricht Protocol for the measurement of body composition and energy expenditure with labeled water. Obesity Research 1995; 3, Suppl. 1: 49-57.

16. Marken Lichtenbelt van WD, Kester A, Baarends EM, Westerterp KR. Bromide dilution in adults: optimal equilibration time after oral administration. J Appl Physiol 1996; 81: 653-656.

17. Schoeller DA. Isotope dilution methods. In: Bjöntröp P, Brodoff BN, eds. Obesity. Philadelphia, J.B. Lippecott Company, 1992; pp. 80-88.

18. Miller ME, Cosgriff JM, Forbes GB. Bromide space 
determination using anion-exchange chromatography for measurement with bromide. Am J Clin Nutr 1989; 50: 168-171.

19. Noll F. L-(+)-lactate, determination with LDH, GTP and NAD. In: Bergmeyer HU, ed. Methods of Enzymatic Analysis. New York, Academic Press, 1974; p. 1475.

20. Schols AMWJ, Soeters PB, Dingemans ANC, Mostert R, Frantzen PJ, Wouters EFM. Prevalence and characteristics of nutritional depletion in patients with COPD eligible for pulmonary rehabilitation. Am Rev Respir Dis 1993; 147; 1151-1156.

21. VanItallie TB, Yan M, Heymsfield SB, Funk RC, Boileau RA. Height-normalized indices of body's fat-free mass and fat mass: potentially useful indicators of nutritional status. Am J Clin Nutr 1990; 52: 953-959.

22. Jones NL. The interpretation of stage I exercise test results. In: Jones NL, ed. Clinical Exercise Testing. Philadelphia, Saunders, 1988; pp. 158-185.

23. Carter R, Peavler M, Zinkgraf S, Williams J, Fields S. Predicting maximal exercise ventilation in chronic obstructive pulmonary disease. Chest 1987; 92: 253-259.

24. Schoeller DA. Changes in total body water with age. Am J Clin Nutr 1989; 50: 1176-1181.

25. Marken Lichtenbelt van W, Westerterp KR, Wouters L, Luijendijk SCM. Validation of bioelectrical-impedance measurements as a method to estimate body-water compartments. Am J Clin Nutr 1994; 60: 159-166.

26. Baarends EM, Schols AMWJ, Pannemans DLE, Westerterp KR, Wouters EFM. Total free living expenditure in severe chronic obstructive pulmonary disease. Am J Respir Crit Care Med 1997; 155: 549-555.

27. Schols AMWJ, Soeters PB, Saris WHM, Wouters EFM. Energy balance in patients with chronic obstructive pulmonary disease. Am Rev Respir Dis 1991; 143: 1248-1252.

28. Nishimura Y, Tsutsumi M, Nakata H, Tsunenari T, Maeda $\mathrm{H}$, Yokoyama M. Relationship between respiratory muscle strength and lean body mass in men with COPD. Chest 1995; 107: 1232-1236.
29. Engelen MPKJ, Schols AMWJ, Baken WC, Wesseling GJ, Wouters EFM. Nutritional depletion in relation to respiratory and peripheral skeletal muscle function in out-patients with COPD. Eur Respir J 1994; 7: 17931797.

30. Telfer N, Bauer FK, Mickey MR, Herbst HH. Body composition in chronic obstructive pulmonary disease. Am Rev Respir Dis 1968; 98: 640-645.

31. Häussinger D, Roth E, Lang F, Gerok W. Cellular hydration state: an important determinant of protein catabolism in health and disease. The Lancet 1993; 341: 1331-1332.

32. Schols AMWJ, Buurman WA, Staal-van den Brekel AJ, Dentener MA, Wouters EFM. Evidence for a relation between metabolic derangements and increased levels of inflammatory mediators in a subgroup of patients with chronic obstructive pulmonary disease. Thorax 1996; 51 : 819-824.

33. Cotes JE, Zejda J, King B. Lung function impairment as a guide to exercise limitation in work-related lung disorders. Am Rev Respir Dis 1988; 137: 1089-1093.

34. Dillard TA, Piantadosi S, Rajagopal KR. Determinants of maximum exercise capacity in patients with chronic airflow obstruction. Chest 1989; 96: 267-271.

35. Wijkstra PJ, Ten Vergert EM, Mark van der ThW, et al. Relation of lung function, maximal inspiratory pressure, dyspnoea, and quality of life with exercise capacity in patients with chronic obstructive pulmonary disease. Thorax 1994; 49: 468-472.

36. Steele B. Timed walking tests of exercise capacity in chronic cardiopulmonary illness. J Cardiopulm Rehabil 1996; 16: 25-33.

37. Lands L, Pavilanis A, Charge TD, Coates AL. Cardiopulmonary response to exercise in anorexia nervosa. Paediatr Pulmonol 1992; 13: 101-107.

38. Kutsuzawa T, Shioya S, Kurita D, Haida M, Ohta Y, Yamabayashi H. ${ }^{31}$ P-NMR study of skeletal muscle metabolism in patients with chronic respiratory impairment. Am Rev Respir Dis 1992; 146: 1019-1024. 